\title{
The Uptake of Modern Contraceptive Methods Among Clients of Post-Abortion Care Services in Urban Guinea
}

\author{
Tamba Mina Millimouno, , , Alexandre Delamou ${ }^{1,2}$, Sidikiba Sidibé ${ }^{1,2}$, Delphin Kolie ${ }^{1}$, \\ Jean Pierre Leno ${ }^{3}$, Thérèse Delvaux ${ }^{4}$, Yolande Hyjazi ${ }^{5,6}$ \\ ${ }^{1}$ Research Unit, National Training and Research Centre in Rural Health of Maferinyah, Forecariah, Guinea \\ ${ }^{2}$ Department of Public Health, Gamal Abdel Nasser University of Conakry, Conakry, Guinea \\ ${ }^{3}$ Health District of Lelouma, Lelouma, Guinea \\ ${ }^{4}$ Department of Public Health, Institute of Tropical Medicine, Antwerp, Belgium \\ ${ }^{5}$ Department of Gynecology and Obstetrics, Gamal Abdel Nasser University of Conakry, Conakry, Guinea \\ ${ }^{6}$ Johns Hopkins Program for International Education in Gynecology and Obstetrics (Jhpiego), Conakry, Guinea \\ Email address: \\ minamillimouno@gmail.com (T. M. Millimouno), mina@maferinyah.org (T. M. Millimouno) \\ ${ }^{*}$ Corresponding author
}

\section{To cite this article:}

Tamba Mina Millimouno, Alexandre Delamou, Sidikiba Sidibé, Delphin Kolie, Jean Pierre Leno, Thérèse Delvaux, Yolande Hyjazi. The Uptake of Modern Contraceptive Methods Among Clients of Post-Abortion Care Services in Urban Guinea. Central African Journal of Public Heal. Vol. 5, No. 5, 2019, pp. 203-211. doi: 10.11648/j.cajph.20190505.14

Received: July 11, 2019; Accepted: August 7, 2019; Published: August 26, 2019

\begin{abstract}
In West Africa, there are limited data on the uptake of modern contraceptive methods among post-abortion care (PAC) clients. This study aimed at describing the knowledge, attitudes and practices of PAC clients towards modern contraceptive methods and identifying the factors associated with the uptake of long-acting contraceptive methods in Guinea. We conducted a cross-sectional study from March to August 2014 with a sample of 426 PAC clients in two communal medical centres in Conakry. Data were collected using a structured questionnaire and analysed using Stata software, version 14. A logistic regression was conducted to identify the factors associated with the uptake of long-acting contraceptive methods. Overall 45,5\% were students, and among them, $66.9 \%$ had a secondary or higher level of education. Among the respondents $21,8 \%$ had a history of abortion. Induced abortion (83.6\%) was the most common type of abortion leading women to seek PAC services. Most of clients (73.6\%) had previously heard about family planning (FP), either at school (42.7\%), in a health facility/pharmacy (26.5\%) or in the neighbourhood (5.9\%). Among them, only 34\% had used a contraceptive method in the last six months prior to the PAC visit. However, 79.1\% of the sample had an unmet need for FP. During the PAC visit, $86.6 \%$ of women expressed a desire to postpone any pregnancy in the next 12 months. Overall, 388 women (91.1\%) adopted a modern contraceptive method. Most of women $(n=375 ; 96.6 \%)$ obtained the chosen contraceptive method before discharge. The intrauterine device (IUD) was the preferred contraceptive method for women $(n=130 ; 34.7 \%)$ followed by implants ( $n=107$; $28.5 \%)$. Having a history of abortion $(\mathrm{OR}=2.5 ; \mathrm{CI}=1.3-4.7)$ and a non-desire for pregnancy in the following $12 \mathrm{months}(\mathrm{OR}=$ 4.8; $\mathrm{CI}=2.0-11.5)$ were the factors statistically significantly associated with the uptake of long-acting contraceptive methods. In our context, induced or unsafe abortion mainly concerned students. There is a need to improve the uptake of contraceptive methods, especially among students and intensify awareness on the consequences of unsafe abortion among youths.
\end{abstract}

Keywords: Uptake, Post-Abortion Care, Modern Contraceptive Methods, Guinea

\section{Background}

Unmet need for family planning (FP) is one of the leading causes of unsafe abortions. If these needs were covered, $84 \%$ of unintended pregnancies would be prevented worldwide [1].
In 2011, 42\% of unintended pregnancies (excluding miscarriages) ended in abortion in United States [2]. Abortion rates have significantly decreased [46 to $27 \%$ o] in the developed countries since 1990, but not in developing countries [39 to $37 \%$ ] where almost all unsafe abortions 
(97\%) are occurring [3-5]. The proportion of maternal deaths attributable to unsafe abortions is high and estimated between $7.9 \%$ [4.7-13.2] and $18 \%$ according to data sources and the methodology used [5-7].

In West Africa, there are limited data on the uptake of modern contraceptive methods among post-abortion care (PAC) clients [8-11].

The adoption of a contraceptive method depends on a variety of factors including the quality of care and availability of contraceptives, the socio-economic and cultural characteristics of the user as well as her knowledge and need for contraception [12].

Providing FP counseling and services to women following abortion or treatment for its related complications has emerged as key strategy among others to address unmet need for contraception in developing countries [13-15]. Following successful pilot experiments in Senegal [15] and Burkina Faso [16], post-abortion care (PAC), including post-abortion FP, were gradually integrated into health facilities in Guinea, starting from 1998 [8], and are now available in 38 health facilities [17-18].

In Guinea, the practice of safe abortion is restricted to situations of foetal malformations or to save woman's life in a context where the contraceptive prevalence remains extremely low at $7 \%$ [19], with a concurrent high unmet need for FP (28\%) reported in 2016 [20]. However, while counseling and modern contraceptive methods are proposed to all PAC clients in a number of health facilities in Guinea, there is no previous study describing these women including in terms of knowledge, attitudes and practices towards FP.

The main purpose of this study was to fill this information gap by describing the knowledge, attitudes and practices of PAC clients towards modern contraceptive methods and identifying the factors associated with the uptake of long-acting contraceptive methods (Implants and Intra-uterine device (IUD)). In addition, we were interested to know more about sociodemographic characteristics and reproductive history of PAC clients in Conakry, Guinea.

Our hypotheses were that standardized and quality FP counseling might increase modern contraceptive methods uptake among PAC clients; having a history of abortion and not willing to be pregnant in the next 12 months would be associated with the uptake of long-acting contraceptive methods.

\section{Methods}

\subsection{Study Design}

A cross-sectional study was conducted from March 01 to August 31, 2014 in the PAC units of two communal medical centres (CMC) in Conakry, Guinea.

\subsection{Settings}

\subsubsection{General Setting}

Guinea is located in West Africa with approximately 11 million inhabitants of whom 15\% live in Conakry, the Capital city [21].

The national health system is composed of primary level
(413 and 726 health centres and posts), secondary level (26 district hospitals and eight communal health centres, seven regional hospitals) and tertiary level (three national hospitals) [19]. Conakry hosts the three national hospitals, five communal medical centres and 21 health centres [21].

PAC were introduced in Guinea in 1998 [6]. The programme started in two national hospitals (Donka and Ignace Deen) and was gradually integrated into 38 other public health facilities including the five CMCs of Conakry (Matam, Ratoma, Coléah, Flamboyants and Minière) between 2005 and 2006 [6].

\subsubsection{Specific Settings}

The PAC units of the Matam and Ratoma CMCs were purposively selected for this study, considering the monthly average number of PAC reported in the five CMCs of Conakry in 2013. The two PAC units accounted for half of the monthly visits recorded in Conakry.

\subsection{Model of Post-Abortion Family Planning Services in Guinea}

Post-abortion FP is usually implemented according to two major methodologies, depending on the legal status of abortion [22]. In countries where abortion is legal, programmes simply provide post-abortion FP services that include advice on FP and the provision of FP services before discharge from the facility. In countries where abortion laws are restrictive and abortion permitted only on specific grounds or forbidden, post-abortion emergency treatment and FP counseling are usually provided in one service while provision of contraceptive methods may need a referral to another service or health facility. Provision of contraceptive methods at post-abortion sites has led to increased adoption of FP and reduced repeat abortions [22]. The second option of post-abortion FP provision is the one used in Guinea.

\subsection{Study Population}

Women admitted to study sites for PAC during the study period who provided written informed consent for participation were included in the study.

\subsection{Study Sample}

We used an exhaustive sampling by consecutively including all women admitted to the post-abortion care units of both communal medical centres during the study period and who provided informed consent.

\subsection{Data Collection and Study Variables}

Data were collected using a structured and standardized questionnaire which was tested at the PAC unit of Donka national hospital.

The study variables included socio-demographic characteristics and reproductive history (age, marital status, husband and woman occupation, number of previous pregnancies, the number of antenatal visits carried out before the abortion, awareness of the free obstetric care policy, type 
of abortion (spontaneous/induced) leading to PAC and the reason for induced abortion) - women's knowledge, attitudes and practices (previous knowledge of FP, source of information on FP, use of any contraceptive method six months before the (index) pregnancy that resulted in abortion, type of contraceptive method used previously, desire for pregnancy in the following 12 months, counseling on FP during the visit, contraceptive method acceptance, obtention of the chosen contraceptive method, type of method chosen, reasons for refusing FP, reasons for not obtaining the contraceptive method chosen and unmet need for FP. In this study, unmet need is calculated based on the proportion of study participants (sexually active) who expressed a desire to avoid pregnancy, space or limit their births in the following 12 months but they had not used any method in the last 6 months [23].

\subsection{Statistical Analyses}

Data were doubly entered using Epidata software (version 3.1) and reconciled to minimize errors. The analyses were performed using Stata software, version 14, Stata Corp, College, Texas, USA.

Descriptive statistics were calculated, as proportions for categorical variables and median with interquartiles for continuous variables. The Pearson Chi square test was used to compare categorical variables and the Student's t-test for continuous variables. A logistic regression was conducted and non-adjusted and adjusted Odds ratios were derived by considering the adoption of a long-acting reversible contraceptive method as a dichotomous variable. All study variables with a $\mathrm{p}$-value $<0.20$ in the bivariate analysis were included in the multivariable logistic regression. The significance level of the regression model was set at $5 \%$, with $95 \%$ confidence intervals.

\subsection{Ethical Considerations}

The research protocol of the study was approved by the scientific committee of the faculty of health sciences and techniques of the Gamal Abdel Nasser University of Conakry. The heads of both health facilities were also contacted and briefed. Written informed consent was obtained from each study participant. For the participation of clients under the age of 16 , written informed consent were obtained from their accompanists who were either the teenager's partner, her parent or a responsible accompanist who was taking care of her. Confidentiality was maintained by removing names and other personal identification information on study forms. The study questionnaire was administered in separate rooms from post-abortion care units to ensure privacy.

\section{Results}

Overall, 3,238 women used maternal health services in the CMCs of Matam and Ratoma during the study period. Of these, $488(15.1 \%)$ sought post abortion care services. 426
$(87.3 \%)$ of these post-abortion care clients consented to participate and were included in this study (Figure 1).

\subsection{Sociodemographic Characteristics and Reproductive History}

The majority of women were single $(61.5 \%)$ and $45.5 \%$ of them were students. Women reaching secondary and university level of education were the most numerous (66.9\%) (Table 1).

The mean number of pregnancies per woman was $2.1 \pm$ 1.1. Among the women, $21.8 \%$ reported a history of abortion. Most women (83.6\%) sought post-abortion services after an induced abortion which was unsafe. The main reasons for these induced abortions were out-of-wedlock pregnancy (56.2\%), short interval between pregnancies $(15.7 \%)$, and poverty $(12.1 \%)$ (Table 2$)$.

\subsection{Knowledge, Attitudes and Practices of Post-Abortion Care Clients Towards Modern Contraceptive Methods}

Overall $73.6 \%$ of the study participants had previously heard about FP, either at school $(n=182,42.7 \%)$, in a health facility/pharmacy $(n=113,26.5 \%)$ or in the neighbourhood $(n=95,5.9 \%)$. Only $34 \%$ had used a contraceptive method in the last six months prior to their visit. Condoms $(n=66$, $45.5 \%)$ and oral contraceptives $(n=62,42.8 \%)$ were the main methods used. During the PAC visit, $86.6 \%$ of women expressed a desire to postpone any pregnancy in the next 12 months including $79.1 \%$ of the sample having an unmet need for FP. All women $(n=426,100 \%)$ received FP counseling from providers and most of them $(n=388,91.1 \%)$ adopted a modern contraceptive method. The modern contraceptive methods obtained by women were mainly IUD $(n=130$, $34.7 \%)$, implants $(n=107,28.5 \%)$ and oral contraceptives $(\mathrm{n}=66,17.6 \%)$. Hence, 237 women $(63.2 \%)$ adopted a longacting contraceptive method. Among the remaining 38 women, the main reasons for refusing modern contraceptive methods were religion $(50 \%)$, refusal of the partner $(21.1 \%)$ or fear of adverse effects (18.4\%) (Table 3$)$.

Among women who adopted modern contraceptive methods, the majority $(n=375,96.6 \%)$ obtained the desired method before discharge. Reasons for not obtaining the desired contraceptive method were the presence of genital infection $(61.5 \%)$ clinically diagnosed by the PAC providers, non-availability of the adopted method $(30.8 \%)$ and the need to seek the opinion of the partner prior to using any contraceptive method (7.7\%) (Table 3$)$.

\subsection{Factors Associated with the Adoption of Long-Acting Contraceptive Methods}

In univariate logistic regression, the factors significantly associated with the adoption of long-acting contraceptive methods were the age of the woman, being married, having a pregnancy in the past, having a history of abortion and, not willing a pregnancy in the next 12 months.

In multivariable analysis, having a history of abortion $(\mathrm{OR}=2.5 ; \mathrm{CI}=1.3-4.7)$ and not willing a pregnancy in the 
next 12 months $(\mathrm{OR}=4.8, \quad \mathrm{CI}=2.0-11.5)$ remained statistically significantly associated with the uptake of long-

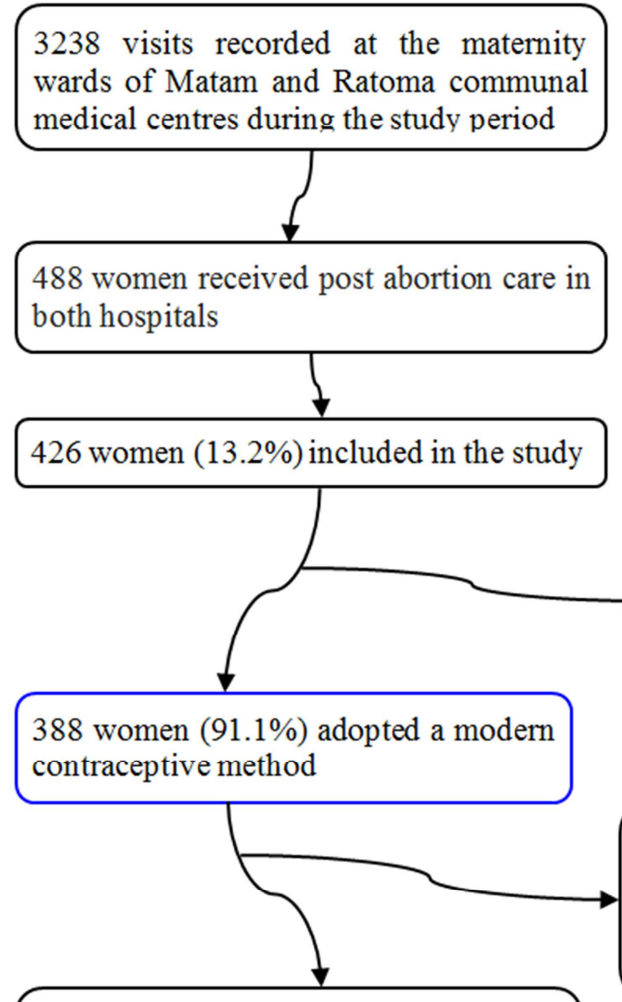

acting contraceptive methods (Table 4).

38 women $(8.9 \%)$ refused adopting a contraceptive method for the following reasons: religion (19), refusal of the partner (8), undesirable effects (7), costs (4)

13 (3.4\%) women did not obtain the contraceptive method adopted for the following reasons: genital infections (8), unavailability of the method (4), Need the opinion of the partner

375 women $(96.6 \%)$ obtained the contraceptive method adopted before discharge

Figure 1. Women inclusion flowchart in the study on the uptake of modern contraceptive methods in two communal medical centres in Conakry, Guinea, March 01-August 31, 2014.

Table 1. Sociodemographic characteristics of post-abortion care clients in two communal medical centres in Conakry, Guinea, March 01- August 31 , 2014 (n $=426)$.

\begin{tabular}{|c|c|c|}
\hline Variables & Number & Percentage (\%) \\
\hline \multicolumn{3}{|l|}{ Age (years) } \\
\hline $15-24$ & 262 & 61.5 \\
\hline $25-34$ & 133 & 31.2 \\
\hline $35-44$ & 31 & 7.3 \\
\hline Median [IQ] & $23.0[20.0-28.0]$ & \\
\hline \multicolumn{3}{|l|}{ Marital status of the woman } \\
\hline Single & 261 & 61.3 \\
\hline \multicolumn{3}{|l|}{ Occupation of the woman } \\
\hline Students & 187 & 45.5 \\
\hline Saleswomen & 70 & 17.0 \\
\hline Workingwomen & 62 & 15.1 \\
\hline Housewife & 60 & 14.6 \\
\hline Employed & 32 & 7.8 \\
\hline \multicolumn{3}{|l|}{ Education level of the woman } \\
\hline None & 92 & 21.6 \\
\hline \multicolumn{3}{|l|}{ Occupation of the spouse } \\
\hline Employed & 131 & 30.8 \\
\hline Salesman & 109 & 25.6 \\
\hline Students & 85 & 19.9 \\
\hline Working men (manual work) & 76 & 17.8 \\
\hline Unemployed & 25 & 5.9 \\
\hline
\end{tabular}

$\mathrm{IQ}=$ Interquartiles 
Table 2. Reproductive history of post-abortion care clients in two communal medical centres in Conakry, Guinea, March 01-August 31, 2014 ( $n=426)$.

\begin{tabular}{lll}
\hline Variables & Number & Percentage (\%) \\
\hline Number of previous pregnancies & & \\
$1-2$ & 294 & 69.0 \\
$\geq 3$ & 132 & 31.0 \\
Median [IQ] & $1.31[1.0-2.0]$ & \\
Age of causal pregnancy (weeks) & & 95.5 \\
$\leq 12$ & 407 & 4.5 \\
$\geq 13$ & 19 & \\
Median [IQ] & $6.0[6.0-8.0]$ & 61.7 \\
Number of ANC completed prior to abortion & & 38.3 \\
None & 263 & \\
One antenatal care & 163 & 76.1 \\
Knowledge of the policy of free obstetric care delivery & & 17.8 \\
Yes & 324 & 6.1 \\
No & 76 & 78.2 \\
Do not know & 26 & 21.8 \\
History of abortion & & \\
No & 333 & 83.6 \\
Yes & 93 & 16.4 \\
Type of abortion leading to the PAC units & & \\
Induced (unsafe) & 356 & 56.2 \\
Spontaneous (incomplete) & 70 & 12.1 \\
Motivation of unsafe induced-abortion (n $=356)$ & & 10.7 \\
Out-of- wedlock pregnancy & 200 & 5.3 \\
Poverty & 43 & 15.7 \\
Reasons related to studying & 38 & \\
Pregnancy not recognized by the partner & 19 & 56 \\
Short interval between pregnancies & & \\
\hline
\end{tabular}

$\mathrm{PAC}=$ Post-abortion care IQ=Interquartiles

Table 3. Knowledge, Attitudes and Practices of post-abortion care clients towards modern contraceptive methods in two communal medical centres in Conakry, Guinea, March 01-August 31, $2014(n=426)$.

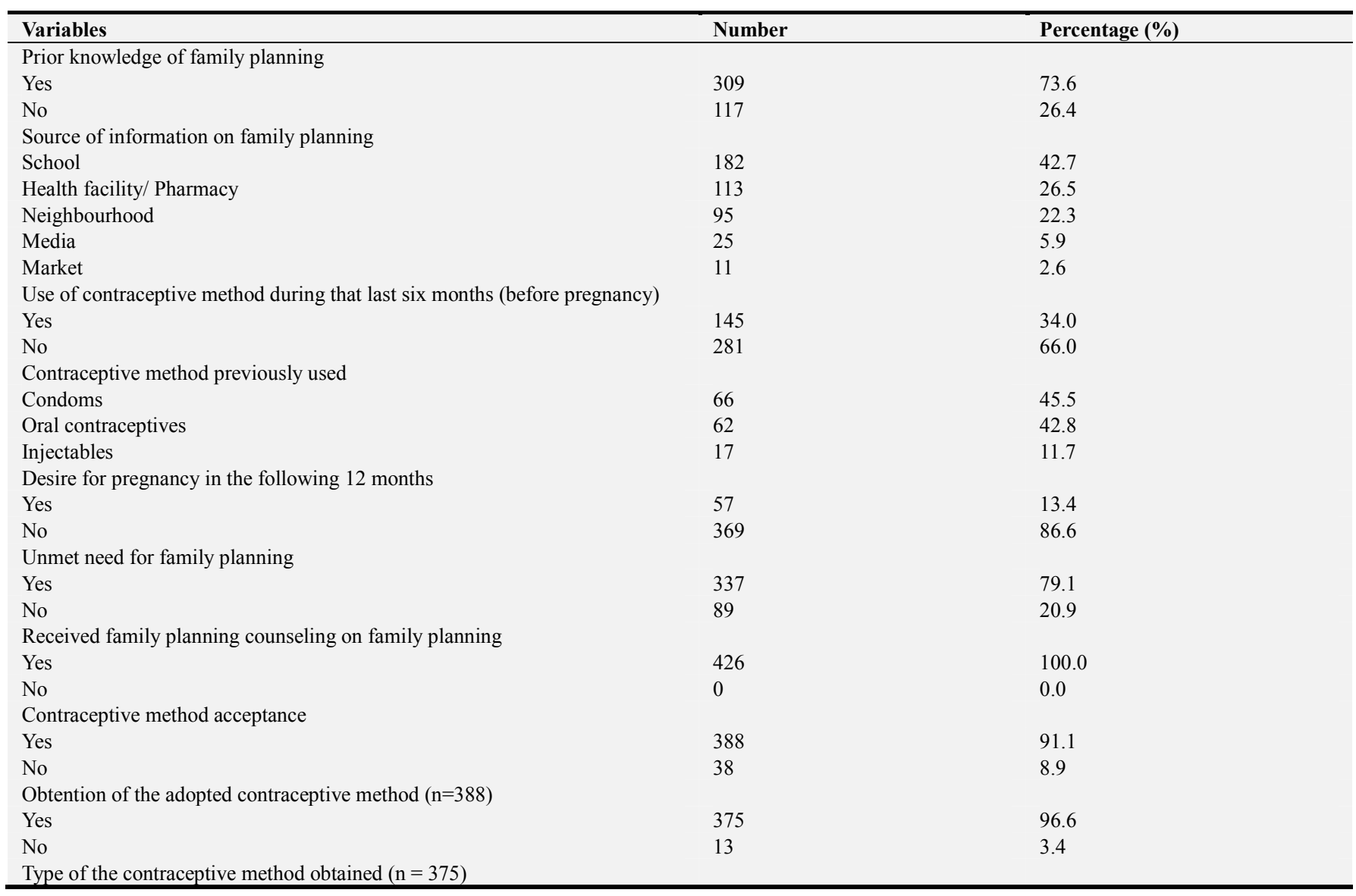




\begin{tabular}{lll}
\hline Variables & Number & Percentage (\%) \\
\hline Intra-uterine device (IUD) & 130 & 34.7 \\
Implants & 107 & 28.5 \\
Oral contraceptives & 66 & 17.6 \\
Injectables & 36 & 9.6 \\
Condom & 36 & 9.6 \\
Reasons for refusing family planning (n=38) & & 50.0 \\
Religion & 19 & 21.1 \\
Refusal of the partner & 8 & 18.4 \\
Undesirable effects & 7 & 10.5 \\
High cost & 4 & 61.5 \\
Reasons for not obtaining the adopted contraceptive method (n=13) & & 30.8 \\
Infection & 8 & 7.7 \\
Non availability of the method adopted & 4 & 1 \\
Need the opinion of the partner & 1 & \\
\hline
\end{tabular}

Table 4. Factors associated with the adoption of long-acting contraceptive methods (Implants and Intra-uterine device) among post-abortion care clients in two communal medical centres in Conakry, Guinea, 1 March - 31 August, 2014 (n=375).

\begin{tabular}{|c|c|c|}
\hline Variables & OR $(95 \% \mathrm{CI})^{\mathrm{a}}$ & ORa $(95 \% \text { CI })^{b}$ \\
\hline \multicolumn{3}{|l|}{ Age (years) } \\
\hline Median & $1.04(1.00-1.08)$ & $1.01(0.95-1.07)$ \\
\hline \multicolumn{3}{|l|}{ Woman marital status } \\
\hline Single (Reference) & 1 & 1 \\
\hline Married & $1.5(1.0-2.4)$ & $1.8(0.8-3.7)$ \\
\hline \multicolumn{3}{|l|}{ Woman occupation } \\
\hline Housewife & $1.3(0.6-2.5)$ & \\
\hline Saleswomen & $1.4(0.7-2.6)$ & \\
\hline Workingwomen & $1.6(0.8-3.1)$ & \\
\hline Employed & $1.1(0.5-2.5)$ & \\
\hline \multicolumn{3}{|l|}{ Woman education level } \\
\hline None (Reference) & 1 & \\
\hline Primary & $1.3(0.6-2.9)$ & \\
\hline Secondary or more & $1.2(0.7-2.0)$ & \\
\hline \multicolumn{3}{|l|}{ Number of previous pregnancies } \\
\hline Median & $1.38(1.16-1.65)$ & $1.17(0.89-1.55)$ \\
\hline \multicolumn{3}{|l|}{ History of abortion } \\
\hline No (Reference) & 1 & 1 \\
\hline Yes & $3.0(1.7-5.3) *$ & $2.5(1.3-4.7) *$ \\
\hline \multicolumn{3}{|c|}{ Type of abortion leading to abortion care units } \\
\hline Spontaneous (incomplete) (Reference) & 1 & \\
\hline Induced (at risk) & $1.2(0.6-2.2)$ & \\
\hline \multicolumn{3}{|l|}{ Knowledge of family planning } \\
\hline No (Reference) & 1 & \\
\hline Yes & $1.1(0.7-1.8)$ & \\
\hline \multicolumn{3}{|c|}{ Family planning usage last six months( before pregnancy) } \\
\hline Yes & $1.3(0.8-2.0)$ & \\
\hline No (Reference) & 1 & \\
\hline \multicolumn{3}{|c|}{ Desire of pregnancy the following 12 months } \\
\hline Yes (Reference) & 1 & 1 \\
\hline No & $2.9(1.4-5.8) *$ & $4.8(2.0-11.5) *$ \\
\hline \multicolumn{3}{|l|}{ Unmet need for family planning } \\
\hline Yes & $1.1(0.6-2.0)$ & \\
\hline No (Reference) & 1 & \\
\hline
\end{tabular}

*Significant at $95 \%$ Confidence level. ${ }^{\mathrm{a}}$ Non-adjusted Odds ratio. ${ }^{\mathrm{b}}$ Adjusted Odds ratio for age, marital status, number of pregnancy, history of abortion and desire of pregnancy in the 12 months following the post-abortion care.

\section{Discussion}

To our knowledge, this is the first study in Guinea to describe the knowledge, attitudes and practices of PAC clients towards modern contraceptive methods and to identify the factors associated with the adoption of long-acting contraceptive methods. The results of this study highlighted some improvements and challenges in the provision of postabortion FP services in Conakry and could be of help to stakeholders and providers.

The main results of this study are that clients of postabortion services in Conakry are mostly youths aged 15 to 24 years (six out of ten), students (about one in two) with six out of ten reaching secondary or university level of education. A study carried out in a rural zone in Ethiopia using a sample of 416 post-abortion clients reported similar results regarding to respondents' age (61\% aged 15 to 24 years) [24]. These results emphasise the need for interventions to prevent 
adolescent and youth unintended pregnancies, especially in schools and universities in Conakry. Efforts should include the provision of quality FP training in schools and universities as well as awareness raising with families and communities to engage in sex education. In addition, there is a need to conduct further research in schools and universities to better understand the reasons underpinning the low use of modern contraceptive methods by students and the frequency of unintended pregnancies in order to guide strategies and interventions design and implementation [25]. However, the high use of post-abortion FP services by literate women might reflect their better access to information on the availability and safety of PAC services in Conakry. Additional efforts should therefore target illiterate women to increase their use of PAC services and thus reduce the equity gap in access to services as observed in this study.

All clients of PAC services received a counseling on FP methods, and most of them adopted and obtained their desired modern contraceptive method before discharge. The results of this study are approximately similar to $94 \%$ acceptance found during an earlier assessment of PAC services conducted in Guinea in 2012 [9, 26].

The observed improvement might be explained by the strengthening of FP counseling, which was effective and informed, and consistently offered to all PAC clients.

And this thanks to the continued technical leadership brought by Jhpiego as well as the mobilization of the resources since the introduction of PAC in Guinea [8-9].

Comprehensive contraceptive information and services should be routinely integrated with abortion and PAC [14, 27].

Studies have reported that the proportion of PAC clients leaving the facility with their desired contraceptive method increases when the FP component is strengthened [28].

It is also known that women who have previously experienced abortion are likely to accept a contraceptive method, even though only $21.8 \%$ of our sample had a history of abortion [12].

Three out of four women from our sample had an unmet need for FP. This could be attributed to lack of information (Knowledge), fear of adverse effects, lack of access (availability, cost, quality), the role of male partners or simply cultural and religious barriers [29-30]. Although our findings are higher than what have been reported at the national level (28\%) [14], there are still challenges to overcome in the provision of quality post-abortion FP services and their extension to cover rural areas where most of illiterate women live [6]. In our study, induced or unsafe abortion was the leading type of abortion motivating the visit to PAC units. In a study conducted in Nigeria in 2015, the proportion of induced abortions was lower than what we observed (35.5\% versus $83.6 \%$ ), and the authors reported that the proportion of induced abortions increased with increasing level of education [31]. In countries where there are legislative restrictions regarding the voluntary practice of abortion, women are exposed to the unsafe induced abortion with unskilled persons [1]. A way to address this issue is to increase awareness raising on the importance of FP in the reduction of unwanted pregnancies and induced abortions [32].

The long-acting contraceptive methods (intra-uterine device and implants) were the most adopted and obtained. This is related to their known efficacy to prevent unintended pregnancy, their long duration of action, their discrete nature and the immediate return to fertility [33]. A study conducted in Conakry in 2015 found contradictory results with injectables being the preferred contraceptive method among women visiting FP clinics in Conakry [34].

In addition, having a history of abortion and not having a desire for pregnancy in the next 12 months were statistically significantly associated with the adoption of a long-acting contraceptive method. Studies have reported that women who have had multiple abortions are more likely to express a need for contraception [35]. It was reported in Kenya in a prospective cohort study of one-year duration that women who did not want to have children in the next three years were more likely to adopt long-acting contraceptive methods [36].

Our study has the merit of providing information that could help health authorities and their partners to support interventions aiming at improving reproductive and maternal health in Guinea. In fact, they trace progress and challenges in providing post-abortion family planning services in Conakry. The implementation and reporting of this study adhered to the internationally recognized STROBE guidelines [37]. However, the cross-sectional nature of our study did not allow us to follow up and analyse the practices of women who adopted long-acting contraceptive methods. In addition, the study took place on two urban health facilities in the Capital. It is possible that the proportions of induced abortions and modern contraceptive methods uptake vary between women in the capital city and those who live in other urban areas and in rural areas in Guinea.

\section{Conclusion}

In our context, induced (unsafe) abortion concerned mainly students. Studies in schools and universities should be carried out for a better understanding of factors associated for not using family planning by these people. Furthermore, community-based post-abortion care mobilization activities should be implemented to expand knowledge of FP methods, raised public awareness of the complications of unsafe abortion and reduced the associated stigma to PAC or family planning. Finally, additional efforts should be made by the health authorities to expand PAC coverage to all district hospitals and health centres in order to reduce maternal mortality.

\section{Authors' Contributions}

TMM, JPL, SS and AD designed the research protocol and the questionnaire. Data collection and entry were carried out by TMM and JPL under the supervision of AD. Data analysis 
was done by AD, SS, TMM and JPL. TMM drafted the manuscript which was critically reviewed by DK, JPL, SS, $\mathrm{AD}$, TD and YH. All authors read and approved the final version of the manuscript.

\section{Conflict of Interest Statement}

All authors declare that they have no conflict of interest

\section{Acknowledgements}

We sincerely thank the health facilities managers and the staff of PAC units of the two CMCs of Matam and Ratoma for their good collaboration during this study. We are grateful as well to women who accepted to participate in the study.

\section{References}

[1] Kassebaum, Global, regional, and national levels and causes of maternal mortality during 1990-2013: a systematic analysis for the Global Burden of Disease Study 2013. Lancet. 2014 Sept; 384 (9947): 980-1004.

[2] L. B. Finer and M. R. Zolna, Declines in unintended pregnancy in the United States, 2008-2011, New England Journal of Medicine, 2016, 374 (9): 843-852, doi: 10. 1056/NEJMsa1506575.

[3] G. Sedgh, J. Bearak, S. Singh, A. Bankole, A. Popinchalk, B. Ganatra et al., Abortion incidence between 1990 and 2014: global, regional, and subregional levels and trends. Lancet. 2016 July 16; 388 (10041): 258-267.

[4] B. Ganatra, C. Gerdts, C. Rossier, B. R. Johnson, Ö. Tunçalp, A. Assifi, et al., Articles Global, regional, and subregional classification of abortions by safety, 2010-14: estimates from a Bayesian hierarchical model. Lancet. 2017; 390 (1016).

[5] L. Say, D. Chou, A. Gemmill, Ö. Tunçalp, A. B. Moller, J. Daniels, et al., Articles Global causes of maternal death: a WHO systematic analysis. Lancet Glob Heal. 2014; 2: e32333.

[6] Guttmacher institute. Adding it up: Investing in Contraception and Maternal and Newborn Health, 2017. Available at: https://www.guttmacher.org/fact-sheet/adding-it-upcontraception-mnh-2017. Accessed on 24/01/2019.

[7] W. Graham, S. Woodd, P. Byass, V. Filippi, G. Gon, S. Virgo, et al., Diversity and divergence: the dynamic burden of poor maternal health. Lancet. September 15, 2016. S01406736 (16): 31533-1.

[8] Jhpiego, Evaluation des soins après avortement en Guinée, Juillet 2007.

[9] F. F. Fikree, S. Mugore and H. Forrester, Soins après avortement: Evaluation des services des soins après avortement dans quatre pays de l'Afrique francophone de l'Ouest (Washington, DC: Projet Evidence to Action, June 2014).

[10] D. R. Sarah, S. K. M. Emmanuel and J. Lori, Post-abortion contraception choices of women in Ghana: A oneyear review. Glob Public Health. 2015; 10 (3): 345-353.
[11] L. Maxwell, G. Voetagbe, M. Paul and A. Mark, Does the type of abortion provider influence contraceptive uptake after abortion? An analysis of longitudinal data from 64 health facilities in Ghana. Maxwell et al. BMC Public Health. 2015; 15: 586

[12] O. E. Loeber and M. E. Muntinga, Contraceptive counselling for women with multiple unintended pregnancies: the abortion client's perspective. Eur J Contracept Reprod Health Care. 2017 Apr; 22 (2): 94-101.

[13] Institut National des Statistiques, Enquête Démographique et de Santé, Guinée 2012.

[14] Institut National de la Statistique, Enquête par grappes à indicateurs multiples (MICS): Rapport final. Conakry, Guinée: Institut National de la Statistique; 2016. Available at: https://mics-surveys-prod.s3.amazonaws.

com/MICS5/West\%20and\%20Central\%20Africa/Guinea/2016 /Final/Guinea\%202016\%20MICS_French. pdf. Accessed on $8^{\text {th }}$ March 2018.

[15] J. Tripney, I. Kwan and K. Bird, Postabortion family planning counseling and services for women in low-income countries: a systematic review. Contraception. 2013; 87 (1): 17-25.

[16] WHO, Safe abortion: technical and policy guidance for health systems, Second edition, 2012. Available at: http://apps.who int/iris/bitstream/10665/70914/1/9789241548434 eng.pdf?ua $=1$. Accessed on $6^{\text {th }}$ October 2018 .

[17] WHO, Health worker roles in providing safe abortion care and post-abortion contraception, 2015. Available at: http://apps.who.int/iris/bitstream/10665/181041/1/978924154 9264 eng.pdf?ua $=1 \& u a=1$. Accessed on $6^{\text {th }}$ October 2018.

[18] S. Suh, "Right tool," wrong "job": Manual vacuum aspiration, postabortion care and transnational population politics in Senegal. Soc Sci Med. 2015 June; 135: 56-66.

[19] S. Drabo, Access to Post Abortion Care (PAC) in Burkina Faso: an ethnographic study. June 2013 (Thesis). Available at: https://www.duo.uio.no/bitstream/handle/10852/36107/Seydo uxDrabo.pdf? sequence $=1$ \&isAllowed $=y$ Accessed on 19 October 2018.

[20] Jhpiego, Stratégie de renforcement de la composante PF dans les SAA en Guinée: SAGO, Niamey 21-25 Janvier 2013, 8p

[21] Institut National de la Statistique, Récensement Général de la Population et de l'Habitation (RGPH). Guinée: Institut National de la Statistique. Avril 2014. Available at: http://www.ins.ci/n/documents/RGPH2014_expo_dg.pdf. Accessed on: $15^{\text {th }}$ April 2018.

[22] C. Curtis, D. Huber and T. Moss-Knight, Planification familiale après avortement: rompre le cycle des grossesses non planifiées et avortements répétés, 2011. Available at: https://www.guttmacher.org/sites/default/files/article_files/37 03111f.pdf. Accessed on $2^{\text {nd }}$ September 2018.

[23] Ministère de la Santé, Plan d'action national pour repositionnement de la planification familiale en Guinée, 2014 - 2018. Guinée, 2014.

[24] G. Hagos, G. Tura, G. Kahsay, K. Haile, T. Grum and T. Araya, Family planning utilization and factors associated among women receiving abortion services in health facilities of central zone towns of Tigray, Northern Ethiopia: a cross sectional Study. BMC Women's Health. 2018; 18: 83. 
[25] A. Delamou, K. Koivogui, D. Dubourg and T. Delvaux, Family planning in Guinea: a need for better public commitment. Tropical Medicine and International Health. January 2014; volume 19 no 1 pp 65-73.

[26] F. F. Fikree, S. Mugore and H. Forrester, Renforcement de la planification familiale après avortement en Guinée, appui technique continu (Washington, DC: Evidence to Action Project, Janvier 2014).

[27] WHO, Ensuring human rights in the provision of contraceptive information and services. Geneva: World Health Organization, 2014. Available a: (http://apps.who.int/iris/bitstream/10665/102539/1/978924150 6748_eng.pdf. Accessed on $20^{\text {th }}$ June 2015).

[28] USAID, Pratiques à Haut Impact dans la Planification Familiale (HIP), Planification familiale après avortement: renforcer la composante de planification familiale dans les soins après avortement. Washington: USAID, November. 2012. Available at: www.fphighimpactpractices.org/resources. Accessed on $30^{\text {th }}$ July 2018.

[29] S. Staveteig, Fear, opposition, ambivalence, and omission: Results from a follow-up study on unmet need for family planning in Ghana. PLOS ONE. July 31, 2017; 12 (7): $\mathrm{e} 0182076$.

[30] J. K. Wulifan, S. Brenner, A. Jahn and M. Manuela De Allegri, A scoping review on determinants of unmet need for family planning among women of reproductive age in low and middle income countries. Wulifan et al. BMC Women's Health. 2016; 16: 2.
[31] M. A. Lamina, Prevalence and determinants of unintended pregnancy among women in South-Western Nigeria. Ghana Medical Journal. Sep2015, Vol. 49 Issue 3, p187-194. 8p.

[32] OMS, Planification familiale: un manuel à l'intention des prestataires de services du monde entier. 2011. p109-133.

[33] Y. B. Amanda, G. Edith, H. Fareen and C. Ismini, The cost of unintended pregnancies in canada: estimating direct cost, role of imperfect adherence, and the potential impact of increased use of long-acting reversible contraceptives. J Obstet Gynaecol Can. 2015; 37 (12): 1086-1097.

[34] A. Delamou, G. Samandari and B. S. Camara, Prevalence and correlates of intimate partner violence among family planning clients in Conakry, Guinea. BMC Res Notes. 2015; 8: 814.

[35] A. Bajracharya, Knowledge, Attitude and Practice of contraception among postpartum women attending Kathmandu Medical College Teaching Hospital. Kathmandu Univ Med J (KUMJ). 2015 Dec; 13 (52): 292-7.

[36] E. O'Neill, J. Tang, J. Garrett and D. Hubacher, Characteristics of Kenyan women in a prospective cohort study who continue using subdermal contraceptive implants at 12 months. Contraception. 2014 Mar 89 (3): 204-8.

[37] E. Von Elm, D. G. Altman, M. Egger, S. J. Pocock, P. C. Gøtzsche and J. P. Vandenbroucke, The Strengthening the Reporting of Observational Studies in Epidemiology (STROBE) statement: guidelines for reporting observational studies. Lancet 2007; 370: 1453-1457. 